\title{
Discursos das juventudes universitárias sobre as políticas de saúde com a população LGBTQIA+ através dos web seminários
}

\author{
Speeches of university youth on health politics with the LGBTQIA+ population through web \\ seminars \\ Discursos de jóvenes universitarios sobre políticas de salud con la población LGBTQIA+ a través \\ de seminarios web
}

\section{Resumo}

As Tecnologias Digitais de Informação e Comunicação possibilitaram o ensino nas escolas e universidades devido às restrições sanitárias causadas pela pandemia da Covid-19. Todavia, o canal online, Web Rádio AJIR, que contabiliza 13 anos de fundação com experiências na produção da comunicação com as juventudes através de programas, web aulas, web seminários, cursos online e entre outras estratégias pedagógicas de promoção do web cuidado educativo em saúde mesmo antes da pandemia, se fortaleceu ampliando seus dispositivos de saberes na formação profissional em saúde. Assim, o objetivo deste estudo foi analisar discursos das juventudes universitárias mediadas nas produções dialógicas dos web seminário, acerca da População LGBTQIA+, desenvolvidos na disciplina de Políticas e Saberes em Saúde Coletiva da graduação em Enfermagem. Esta pesquisa se caracterizou como documental, descritiva e qualitativa, com a participação de 56 jovens que produziram perguntas-discursos que denotando lacunas destes conteúdos na formação e prática profissional no cotidiano da assistência direta no Sistema Único de Saúde, sendo requisitados mais conteúdos sobre os cuidados em saúde para com a população que reivindica à equidade, a integralidade e acesso universal à assistência nos serviços de saúde como direito humano. Concluiu-se, que ao abordar as políticas de equidade com universitários despertou a compreensão para o cuidado ampliado e a utilização das tecnologias digitais da comunicação como produtores de práticas de web cuidado, além de considerar às histórias de vidas, as singularidades, o respeito à diversidade sexual, de gêneros e a dignidade humana de LGBTQIA+.

Palavras-chave: Enfermagem; Saúde; Tecnologia; Sexualidade; Identidade de gênero; Covid-19.

\section{Abstract}

Digital Information and Communication Technologies have made it possible to teach in schools and universities due to the health restrictions caused by the Covid-19 pandemic. However, the online channel, Web Radio AJIR, which accounts for 13 years of foundation with experiences in the production of communication with young people through programs, web classes, web seminars, online courses and among other pedagogical strategies for the promotion of 
educational web care in health even before the pandemic, has been strengthened by expanding its devices of knowledge in professional training in health. Thus, the objective of this study was to analyze discourses of university youth mediated in the dialogical productions of web seminars about the LGBTQIA+ population, developed in the discipline of Policies and Knowledge in Collective Health in the undergraduate nursing course. This research was characterized as documentary, descriptive and qualitative, with the participation of 56 young people who produced questions-discourses denoting gaps in these contents in professional training and practice in everyday direct care in the Unified Health System, being requested more content on health care for the population that claims equity, completeness and universal access to care in health services as a human right. It was concluded that when addressing equity policies with university students, it awakened the understanding of expanded care and the use of digital communication technologies as producers of web care practices, in addition to considering life stories, singularities, respect for sexual and gender diversity, and the human dignity of LGBTQIA+ people.

Keywords: Nursing; Health; Technology; Sexuality; Gender identity; Covid-19.

\section{Resumen}

Las Tecnologías Digitales de la Información y la Comunicación hicieron posible la enseñanza en escuelas y universidades debido a las restricciones sanitarias causadas por la pandemia del Covid-19. Sin embargo, el canal en línea, Web Radio AJIR, que cuenta con 13 años de fundación con experiencias en la producción de comunicación con los jóvenes a través de programas, clases web, seminarios web, cursos en línea y entre otras estrategias pedagógicas para la promoción de la atención web educativa en la salud incluso antes de la pandemia, se ha fortalecido mediante la ampliación de sus dispositivos de conocimiento en la formación profesional en salud. Así, el objetivo de este estudio fue analizar los discursos de los jóvenes universitarios mediados en las producciones dialógicas de los webinars sobre la población LGBTQIA+, desarrollados en la disciplina de Políticas y Saberes en Salud Colectiva del curso de pregrado de enfermería. Esta investigación se caracterizó por ser documental, descriptiva y cualitativa, con la participación de 56 jóvenes que produjeron preguntas-discursos que denotan vacíos en estos contenidos en la formación y práctica profesional en la rutina diaria de la atención directa en el Sistema Único de Salud, siendo solicitados más contenidos sobre la atención a la salud de la población que reclama equidad, integralidad y acceso universal a la atención en los servicios de salud como un derecho humano. Se concluye que al abordar las políticas de equidad con los universitarios, se ha despertado la comprensión del cuidado ampliado y la utilización de las tecnologías digitales de la comunicación como productoras de prácticas de cuidado web, además de considerar las historias de vida, las singularidades, el respeto a la diversidad sexual, de género y la dignidad humana de LGBTQIA+. Palabras clave: Enfermería; Salud; La tecnologia; La sexualidade; Identidad de género; Covid-19.

\section{Introdução}

A Organização das Nações Unidas para a Educação, a Ciência e Cultura (UNESCO), considera que a Educação tem sido o campo social mais afetado pelas dificuldades e desafios que as juventudes têm enfrentado no contemporâneo pandêmico da Covid-19 que nos impôs restrições sanitárias, afetando a convivência social de estudantes, professores e funcionários de escolas e universidades que tiveram suas atividades transportadas para o ensino remoto emergencial na Internet, afetando mais de $90 \%$ dos estudantes do mundo (Unesco, 2020).

No entanto, o uso das Tecnologias Digitais de Informação e Comunicação (TDIC) ganhou mais visibilidade para uso didático no ensino diante das restrições sanitárias causadas pela pandemia da Covid-19, onde os ciberespaços da Internet utilizados para o entretenimento, debates políticos e econômicos, deram lugar ao ensino na modalidade remota com as juventudes.

Assim, o uso da TDIC integrada às atividades cotidianas no contemporâneo da Covid-19 possibilitou ampliar as relações humanas, visto que o desenvolvimento tecnológico conectado à Internet expandiu a intensidade e as possibilidades do seu uso no campo educacional, possibilitando novas formas de comunicação e socialização dos saberes nos ciberespaços (Mallmann, et al., 2012).

Compreende-se como ciberespaço ou espaço virtual ambientes criados para conectar pessoas com interações síncronas e assíncronas, possibilitando armazenamento de conteúdos, dados, linguagens e estéticas nativas mutantes que integram variados substratos da comunicação visual, computacional, design de estético e éticos constituídos na cibercultura (Lévy, 1996).

Estes ciberespaços não são realidades virtuais expandidas e interconectadas como se fossem uma outra galáxia 
planeta, mas é mesmo uma realidade virtual suspensa na organização algorítmica computacional apinhadas por pontos disruptivos como agenciamentos das relações sociais cotidianas, uma navegação no outro lado onde a vida pública e privada perpassada pela captura das tecnologias digitais como uma economia das trocas simbólicas da vida que é em outro modo engendrado da vida humana complexa no mundo globalizado (Lemos, 2002; Bourdieu, 2007).

Neste sentido, o canal online, web rádio, já contabiliza 13 anos de criação e funcionamento com experiências de produções de informações e comunicações com as juventudes escolares e universitárias. Neste tempo de produção de conteúdo educativo no digital desenvolveu-se um processo didático e pedagógico, através de web aulas, web seminários, cursos, entre outros, como formas de promover o web cuidado educativo em saúde para o público que acessa a Internet.

Contudo, está comunicação para o web cuidado clínico e educativo em saúde com as juventudes se materializa na virtualidade através do Programa "Enfermagem Digital". Este, com efeito, faz-se pelas produções discursivas dos (as) participantes, com perguntas e inquietações, como efeito de poder e saber na circularidade do conhecimento nas mediações no espaço digital da web rádio (Torres, 2020).

Neste sentido, a importância do uso desses ciberespaços, diz respeito a sua capacidade de conectar todos em uma realidade virtual para promover o cuidado, abordar temáticas que se configuram em necessidades que são muitas vezes desconsideradas, tais como das populações Lésbica, Gay, Bissexual, Transexual, Queer, Intersexual, Assexual, Agênero e todas as denominações não heterossexual (LGBTQIA+) que ao longos dos anos vem alterando sua sigla no intuito de abranger todos e todas as pessoas com suas diversidades e diferenças.

Estas necessidades estão no esteio da discriminação social e do preconceito enfrentado pelas populações LGBTQIA+ que desafiam as iniquidades e vulnerabilidades que afetam sua saúde, portanto, a inserção desses conteúdos em disciplinas de cursos de formação de profissionais da saúde é de suma importância, pois ao problematizar os padrões "normativos" da cultura conservadora que impera nas relações dos profissionais da saúde com a população LGBTQIA+ poderá facilitar o atendimento equitativo e diferenciar ao observar as singulares que têm estes sujeitos.

Assim, analisou-se os discursos das juventudes universitárias sobre a saúde das Populações LGBTQIA+ dialogadas nos web seminários produzidos como conteúdo de comunicação do Programa Enfermagem Digital no canal online, Web Rádio AJIR.

\section{Metodologia}

Pesquisa documental, qualitativa e descritiva com a análise dos saberes produzidos e armazenados nos repositórios e nas plataformas digitais, YouTube, WhatsApp, do Programa: Enfermagem Digital no canal online, web rádio. Os estudos qualitativos, de acordo com Polit e Beck (2011), tem caráter flexível e elástico, capaz de se ajustar ao que vai sendo descoberto e com frequência envolve uma mescla de várias estratégias de coleta de dados (...), buscando uma compreensão do todo, exigindo intenso envolvimento dos(as) sujeitos(as) participantes da pesquisa.

O Programa: Enfermagem Digital é uma estratégia didática na disciplina Política e Saberes em Saúde Coletiva do curso de graduação em Enfermagem da Universidade Estadual do Ceará onde ocorre diálogos a respeito das diversas temáticas discutidas na atualidade com enfoque na saúde, e que também hospeda os web seminários realizados por essa juventude universitária, onde permitem-lhes protagonizar o cuidado em saúde através de debates.

A produção dos programas ocorreu em Fevereiro de 2021, com interações com as juventudes de quatro instituições de ensino superior do Ceará, de modo virtual pela plataforma do Google Meet e com transmissão para o link oficial da Web Rádio AJIR, www.uece.ajir.com.br, com áudio e vídeo pelo Youtube disponibilizado como desenho de web tv neste site. Os temas contemplados foram Políticas de Saúde com as Populações LGBTQIA+.

Ressalta-se que Web Rádio AJIR, fundada em 2007 para desenvolvimento de conteúdos de comunicação de 
promoção do cuidado educativo com as juventudes, contabiliza muitos conteúdos e produtos gerados no intuito de elevar a saúde das juventudes e fortalecimentos de Políticas de Promoção da Saúde nas escolas e universidades.

Todavia, os dados deste estudo foram produzidos no contexto da pandemia da Covid-19 que afeta o Brasil e o mundo, que vem ceifando muitas vidas em 2020 e 2021. Entretanto, os conteúdos de comunicação com interações virtuais como desenho de prática de web cuidado em saúde com as juventudes através da web rádio foram centralizados nas ações de prevenção da pandemia através de diálogos científicos e sociais sobre a Covid-19 (Torres, 2020a).

Também, a opção pelo termo "juventudes", se refere às experiências destes sujeitos produzidas em territórios culturais diversos pelos modos de vida juvenis, sem, contudo, a pretensão de expor os agenciamentos identitários e não identitários na construção etária, do binarismo de gêneros, classe social, raça-cor, entre outros (Torres, 2020a; Sales, 2016).

Logo, os dados coletados nos web seminários foram sistematizados e organizados como "perguntas-discursos" dos participantes e analisadas como práticas discursivas das juventudes ao cuidar de si, com atos de "falas" mediadas nos espaços digitais, no contexto do contemporâneo pandêmico (Torres, 2019; Torres, 2020a; Torres, 2021).

Considerou-se como Perguntas-Discursos (PD) dos(as) participantes, que foram comentários, indagações, perguntas, sobre a temática debatida nos web seminários sobre as políticas de saúde com a população LGBTQIA+. Contudo, as PD foram sistematizadas em categorias temáticas: Categoria 01 - Discursos: preconceito, estigma e homofobia e a Categoria 02 Discursos: heteronormatividade, garantia de direitos e atendimento à saúde. Também, no sentido de preservar as "regras" éticas no estudo, identificou os(as) participantes como Jovem Universitário (JU1), (JU2), (JU 3).

Assim, as categorias temáticas seguiram a "análise de discurso (AD)", como modos de dá "rostos" as experimentações juvenis produzidas no digital como "atos de falas, escritas, gravadas, filmadas, desenhadas" sobre as políticas de saúde com as populações LGBTQIA+. Pois, sobretudo, são estes enunciados discursivos que constituem o cuidado de si, através da comunicação em saúde e que engendram as práticas de web cuidado (Foucault, 2006; Torres, 2019; Torres, 2020; Torres 2020a; Torres 2021).

Destarte, este teve aprovação do Comitê de Ética em Pesquisa da Universidade Estadual do Ceará, (Parecer no. 1.761.115/2019) e foi guiado pela Resolução 466/2012 do Conselho Nacional de Saúde (Brasil, 2012).

\section{Resultados}

O Programa: Enfermagem Digital hospedou os conteúdos dos web seminário realizados com 59 jovens universitários como estratégia didática na disciplina Política e Saberes em Saúde Coletiva do curso de graduação em Enfermagem da Universidade Estadual do Ceará. A turma desta disciplina foi dividida em grupos com quatro integrantes, nos quais, ficaram responsáveis pela produção do roteiro, preparação da locução do programa, como também da Pergunta-âncora, idealizada pelo coordenador e criador do canal online, como um modo de motivar os discursos dessas juventudes com a extensão da comunicação dialogada no programa. Este foi organizado em três blocos, onde os integrantes se dividiram em locutor, entrevistado e comentarista das interações, computando 1 hora de conteúdo produzido sincronicamente na web rádio.

No gráfico a seguir descreve-se a caracterização dos participantes de acordo com seu curso de graduação e Unidade de Ensino Superior, que estiveram presentes como participantes ativos nos web seminário produzidos na web rádio. 
Figura 1: Caracterização dos participantes segundo curso e unidade de ensino que compõem a audiência do Programa Enfermagem Digital, Fortaleza - Ceará, 2021.

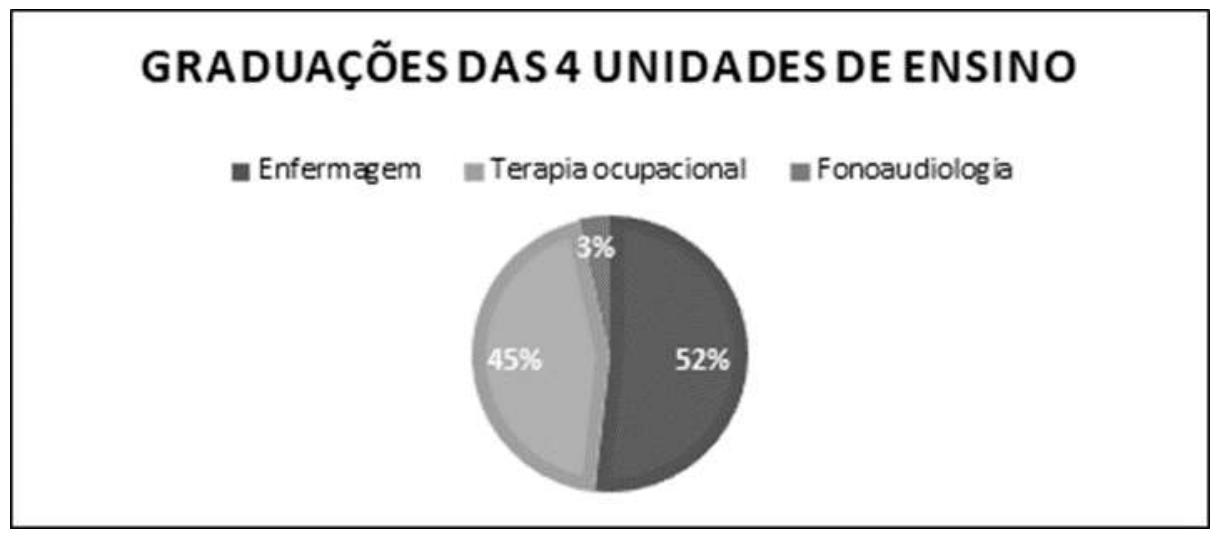

Fonte: Autores (2021).

Na Figura 1 nota-se que 52\% dos participantes eram jovens das graduações em Enfermagem, seguido de 3\% da Fonoaudiologia e $45 \%$ da Terapia Ocupacional, compuseram o público do Programa: Enfermagem Digital. Destaca-se a identificação das instituições de ensino superior: Centro Universitário de Juazeiro do Norte, Centro Universitário UNINTA de Sobral, Universidade Estadual do Ceará e Universidade Regional do Cariri na cidade de Iguatu-Ceará.

O contexto da pandemia causada pela Covid-19 possibilitou o uso com muita frequência das Tecnologias Digitais da comunicação no ciberespaço da Internet, isso mostrou a forte migração de vários campos para este lugar do digital. Entretanto, na web rádio, os conteúdos de educação em saúde já eram desenhados desde 2007. Porém, para as aulas remotas, cursos, programas, as juventudes universitárias passaram a navegar em outras experimentações, como o uso aumentado dos canais do Youtube para momentos ao vivo e programas. Isto pode ser observado nos modos de participação das juventudes nos web seminários que estão descritas no fluxograma.

Figura 2: Fluxograma das participações das juventudes no Programa: Enfermagem Digital, Fortaleza-Ceará, 2021.

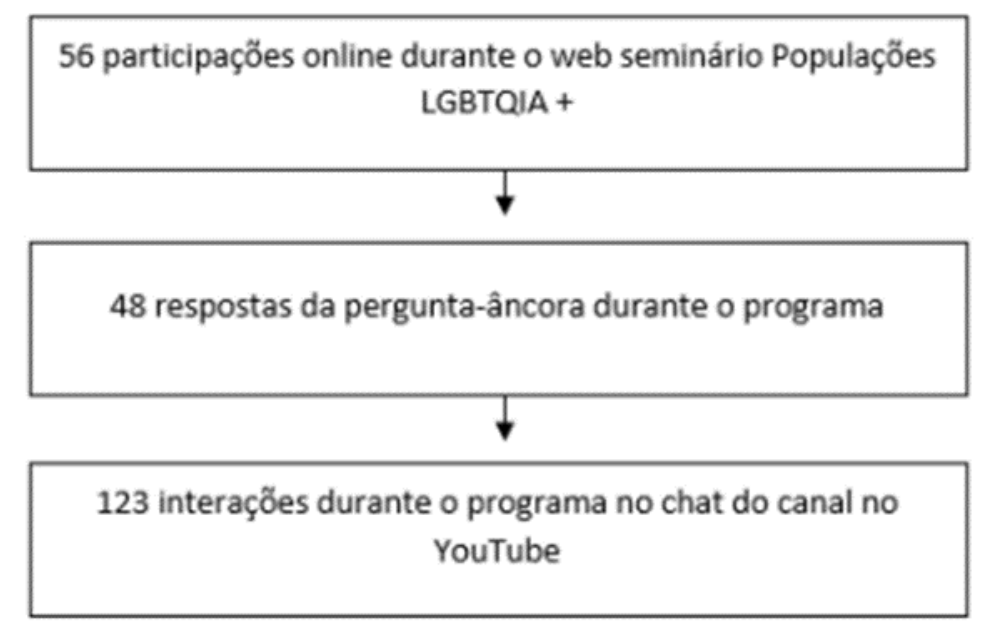

Fonte: Autores (2021).

No Programa: Enfermagem Digital 56 jovens se fizeram presentes durante a transmissão online, problematizando a Pergunta Âncora (P.A) que versou sobre: “A $1^{\circ}$ Conferência Nacional de Gays, Lésbicas, Bissexuais, Travestis e Transsexuais 
(GLBT) trouxe um marco importante que foi a aprovação da sigla LGBT, portanto, qual o ano de realização desta conferência?" E que foi respondida no formulário online que abriga a PA e que 47 jovens responderam "corretamente" no ano de 2010.

Apesar do bom envolvimento e acertos na P.A, notou-se que as interações dos jovens não trouxeram perguntas acerca do tema específico, o que poderia soar como algo negativo para a pesquisa, mas para Foucault (2013), em a Arqueologia do Saber, a primeira instância que seria a instância dos enunciados, na produção discursiva, o silêncio também considera-se como um discurso, pois o silêncio revela que é algo de pouco interesse ou algo velado na sociedade em qual essa juventude vive, a qual não desperta curiosidade ou até mesmo uma certa inibição para se abordar sobre o tema, o que mostraria em que relações de poder aquela juventude encontra-se no contexto social.

O discurso do "não falar sobre" pode justificar a ausência das perguntas, e a longo prazo, pode relacionar-se ao negacionismo no enfrentamento dos desafios frente a situações de agravos e adoecimento dessa população que busca o atendimento de saúde, tendo como resposta a ausência do cuidar. Desta forma, o impacto desse discurso "não dito" produz um apagamento das demandas em saúde da população LGBTQIA+, bem como tende a desqualificar a necessidade de ações específicas para essa comunidade. Uma vez que as necessidades não são explicitadas/reconhecidas, a equipe e o Sistema de Saúde se eximem de qualquer responsabilidade ou ação em prol do cuidado em saúde dessas pessoas (Paulino, 2019).

Na produção dos web seminários com o tema LGBTQIA+, a equipe de jovens universitários iniciou a apresentação, em seu primeiro bloco, destacando a importância da representatividade pelas simbologias das "letras na sigla" e o porquê da contínua mudança delas, que representa uma marcação política das identidades costuradas na diversidade humana e com reforço no contexto histórico em que os movimentos sociais deste campo enfrentaram para o reconhecimento social dos direitos humanos da comunidade LGBTQIA+.

No segundo bloco do programa foi abordado a portaria $\mathrm{N}^{\circ} 2.836$, de $1^{\circ}$ de dezembro de 2011 que se refere a promoção da saúde com equidade as populações vulneráveis, explorando os objetivos, diretrizes, responsabilidades e atribuições desta política. Assim, neste bloco, as juventudes possibilitaram reflexões sobre o que vem sendo desenvolvido como ações da política de saúde para com LGBTQIA+.

Isto demonstrou como as juventudes universitárias estão contribuindo para a publicização dos direitos dos(das) LGBTQIA+, reforçando a necessidade dessa temática dentro da formação de graduação em saúde, o que poderá auxiliar no conhecimento e desenvolvimento de programas de assistência em saúde e de acesso, desta população, aos serviços de saúde do Sistema Único de Saúde.

Neste contexto, a Política Nacional de Saúde Integral da população LGBTQIA+, constitui-se de um ladrilho deste caminho, estabelecendo a necessidade do cuidado transversal em saúde dentro do Ministério da Saúde e os demais entes federados, sobretudo no tocante a eliminação da "discriminação e do preconceito institucional, bem como contribui para a redução das desigualdades e a consolidação do Sistema Único de Saúde e seus princípios da universalidade, integralidade e equidade" (Brasil, 2013).

Seguindo a dinâmica de produção dos web seminários, no terceiro bloco, a equipe fez referência aos comentários dos(as) participantes postadas nos chats dos canais de comunicação da web rádio e sistematizado no Quadro 1. 
Quadro 1: Apresentação das perguntas-discursos produzidos no web seminário como conteúdo do Programa: Enfermagem Digital produzidos na Web Rádio AJIR-UECE, Fortaleza - Ceará, 2021.

\begin{tabular}{|c|c|c|}
\hline Perguntas-Discursos & Categorias Temáticas & Identificação \\
\hline $\begin{array}{l}\text { "Sim, muito interessante esse assunto até porque essa } \\
\text { população infelizmente, sofre muito estigma", }\end{array}$ & Estigma, preconceito & $\begin{array}{l}\text { Jovem Universitário } 1 \text { - curso de } \\
\text { Enfermagem }\end{array}$ \\
\hline $\begin{array}{l}\text { "Infelizmente muita gente não acha necessário falar } \\
\text { desse assunto", }\end{array}$ & Heteronormatividade & $\begin{array}{l}\text { Jovem Universitário } 2 \quad- \\
\text { Curso Fonoaudiologia }\end{array}$ \\
\hline '’Momento muito rico e muito importante a temática ', & $\begin{array}{l}\text { Profissionais de saúde } \\
\text { capacitados para a temática }\end{array}$ & $\begin{array}{l}\text { Jovem Universitário } 3 \text { - Curso de } \\
\text { Terapia Ocupacional }\end{array}$ \\
\hline $\begin{array}{l}\text { "Importante ressaltar sobre respeitar o nome social dos } \\
\text { participantes dessa comunidade", }\end{array}$ & Garantia de direitos & $\begin{array}{l}\text { Jovem Universitário } 4 \text { - Curso } \\
\text { Terapia Ocupacional }\end{array}$ \\
\hline $\begin{array}{l}\text { 'É muito triste também, saber que o Brasil é o país que } \\
\text { mais mata Transsexuais no mundo e é o país que lidera } \\
\text { consumo de pornografia trans"' }\end{array}$ & Crimes por homofobia & $\begin{array}{l}\text { Jovem Universitário } 5 \text { - Curso } \\
\text { de Enfermagem }\end{array}$ \\
\hline
\end{tabular}

Fonte: Autores (2021).

As perguntas-discursos das juventudes dão visibilidades sobre os preconceitos, estigmas, homofobias, mas também apontaram a necessidade da luta política pelos direitos humanos e a qualificação profissional na saúde, pois são esses sujeitos que operarão as políticas de saúde com os(as) LGBTQIA+. Assim, os debates sobre os conceitos de gêneros, identidades de gêneros e sexuais, diversidade de gêneros pode possibilitar a compreensão da diversidade que comporta as relações humanas produzidas na vida social. Contudo, problematizar sobre tabus e mitos que nossa sociedade machista, sexista, homofóbica e opressora pratica cotidianamente é reafirmar a necessidade das garantias dos direitos humanos pelo Estado. Pois desconstruir discursos que romantizam o sofrimento e a ideia de liberdade dos corpos, dos desejos, das identidades, entre outros, não poderá ser verbalizado como futuro, mas sim como luta política pelos direitos de LGBTQIA+ no presente, neste momento contemporâneo pandêmico da Covid-19.

Neste sentido, Lionço (2008) argumenta que o processo de construção de serviços não discriminatórios na área da saúde enfrenta diversas barreiras diante de uma sociedade na qual a heterossexualidade se configura como um padrão amplamente difundido e cultuado. Assim, as perguntas-discursos das juventudes nos web seminários mostraram a necessidade dos conteúdos sobre as políticas de saúde com públicos específicos na formação dos profissionais de saúde, considerando as garantias dos direitos das populações que sofrem vulnerabilidades sociais, como são os(as) LGBTQIA+, de modo que a ação equitativa e integral possa se fazer como prática de cuidado no cotidiano dos serviços de saúde.

\section{Discussão}

Os web seminários produziram práticas discursivas que nada mais são que o conjunto de enunciados, que não podem ser vistos apenas como signos, mas precisam serem vistos em detalhes pois trazem a riqueza de quem fala, de quem se fala, das instituições que são incitadas, do local em que se fala, e como repercutem na sociedade. Assim, compreende-se que os discursos são dispositivos históricos e políticos construídos no contexto social de cada um, por uma realidade em particular, portanto, não correspondem cópias exatamente reguladas e reproduzidas (Foucault, 2012). 
Contudo, os discursos das juventudes universitárias engendram suas realidades culturais e históricas como dispositivos de palavras e coisas que montam seus modos de dizer e fazer suas artes de vida. Com efeito, os discursos também possibilitam construirmos categorias temáticas que foram sistematizadas fazendo sempre a espiral com o campo central do estudo, as políticas de saúde com LGBTQIA+.

\subsection{Categoria 01 - Discursos: preconceito, estigma e homofobia}

A Associação Nacional de Travestis e Transexuais e o Instituto Brasileiro Trans de Educação (2021), revelaram que o Brasil ocupa o $12^{\circ}$ ano consecutivo como país que mais mata pessoas trans, tomando o primeiro lugar neste ranking e em seguida vem o México e os Estados Unidos. Contabilizou-se 175 assassinatos notificados em 2020 contra pessoas que expressavam publicamente seu gênero feminino em contraposição ao gênero designado ao nascer (Antra, 2021). Este quadro epidemiológico de assassinatos de LGTQIA+, ocorre em nosso país mesmo com a decisão do Supremo Tribunal Federal de reconhecer a LGBTfobia como uma forma de crimes imputáveis e com prescrição das devidas penalidades.

No relatório observatório de mortes violentas de LGBTQIA+ no Brasil realizado pelo movimento Grupo Gays da Bahia (2021), relatou que em 2020 os números de mortes nesta comunidade tiveram uma diminuição, quando comparado ao ano de 2019, resultando em 28\% de diferença. Pois mesmo sendo registrado 237 mortes no Brasil motivadas por LGBTfobia essa diminuição nos números não decorre de nenhuma ação do governo central, mas do contexto de enfrentamento da pandemia causada pela Covid-19, em que os estados brasileiros decretaram como medidas sanitárias, o isolamento social e regras de acesso restrito aos serviços essenciais. Todavia, mesmo neste contemporâneo pandêmico persiste um quadro caótico no ranking de 20 municípios do Brasil, onde Fortaleza/Ceará, encontra-se em primeiro lugar no número das mortes de LGBTQIA+ em 2020 (GGB, 2021).

Neste sentido, não se percebe ações do Estado para proteção dessa população, visto que os gráficos de notificação de assassinatos sobem exponencialmente e geram alertas para o aumento da vulnerabilidade das pessoas trans em meio à pandemia da Covid-19, sobretudo, porque as medidas emergenciais, como auxílio emergencial, não consegue assegurar a não precarização histórica que LGBTQIA+ vivem, sendo necessário permanecerem em seus trabalhos, com exposições públicas ao vírus e, consequentemente, à violência transfóbica.

Assim, considera-se que os discursos das juventudes universitárias apontam para visibilidade desta conjuntura vivenciada pelas pessoas que fazem parte desse segmento excluído e violentado socialmente, pois são sujeitos das margens, das beiras, dos guetos, que não se adaptaram aos padrões heteros-cis-normativos. Este contexto reverbera em nosso país na situação de miserabilidade e exclusão social em que vive a população Trans, sem acesso à educação, saúde, qualificação profissional, oportunidade de inclusão no mercado de trabalho formal e políticas públicas que considerem suas demandas específicas (Antra, 2019). Todavia, é necessário destacar como os movimentos sociais, coletivos, militantes, ativistas pesquisadores(as) LGBTQIA+, colocam em seus megafones, nas redes sociais e em outros canais de comunicação, a defesa da vida e dos direitos humanos desta população, denunciando os discursos de ódio, da homofobia e das violências penetradas cotidianamente, que repercute como efeito da heteronormatização nas produções discursivas hegemônicas na sociedade moderna e contemporânea.

Passa-se a análise da Categoria 02 em que estas "normas" que regulam as sexualidades na vida social e a garantia dos direitos à saúde seja universal, equânime e integral são exploradas com ancoragem nos discursos das juventudes universitárias. 


\subsection{Categoria 02 - Discursos: heteronormatividade, garantia de direitos e atendimento à saúde}

As implicações da heteronormatividade vista como o 'padrão' da sociedade, torna-se a principal chave para a compreensão de atitudes discriminatórias e negligentes com a comunidade LGBTQIA+ nos serviços de saúde e em outras esferas institucionais. Isto pode ser localizado nos discursos realizados por essa juventude que demonstraram não haver interesse por parte da sociedade no desenvolvimento das políticas e direitos destas populações.

Todavia, a definição de heteronormatividade é entendida como a reprodução de práticas e códigos heterossexuais, sustentados pelo casamento monogâmico, amor romântico, fidelidade conjugal, constituição de família (esquema pai-mãe-filho (a) (s)) (Foster, 2001). Para Fraser (2003), "Padrões valorativos heteronormativos também penetram na cultura popular e na interação cotidiana. O resultado é construir gays e lésbicas como uma sexualidade desprezada, sujeitos a formas sexualmente específicas de subordinação de status."

Esta alusão pode ser vista nos discursos das jovens universitárias na graduação em enfermagem, quando destacam que o rompimento da visão heteronormativa tem ganhado espaços nas mídias, seja por TV aberta, filmes, séries, novelas, jornais, entre outras, assim como cargos ocupados, meritoriamente, por pessoas públicas heterossexuais, que defendem os debates sobre as sexualidades e gêneros como construção social e cultural e que fala sobre população LGBTQIA+ não interfere na orientação sexual ou identidade de gênero de crianças, adolescentes e jovens e possibilitam desmistificar as "fakes news" difundidas pelo governo central da república do nosso país, como capitaneamento político com as classes e o conservadorismo que pregam o discurso de ódio e a homofobia como defesa da manutenção dos valores morais das famílias heteronormativas e das "normas" religiosas cristãs fundamentalistas.

Neste sentido, pesquisas de Mahdi et al. (2014), com os profissionais de enfermagem, obtiveram escores altos de preconceito quanto ao atendimento do público LGBTQIA+. Com isso, se faz necessário a problematização deste tema na formação em saúde e enfermagem tendo em vista que são com estes profissionais que é feito o primeiro contato dentro de uma Unidade Primária à Saúde. Portanto, a educação problematizadora que aponta para o respeito e a não discriminação da população, seja de qualquer orientação sexual e de gênero, deverá ser motivada nas universidades utilizando canais de comunicação, como web rádio, blogs, redes sociais, entre outros ciberespaços na Internet.

No tocante às garantias dos direitos da população LGBTQIA+ ainda passa por grandes percalços, pois, mesmo com resoluções, leis, portarias abrangendo a criminalização da LGBTfobia, ainda impera casos de intolerância e violação dos direitos humanos, ceifando vidas pelo não reconhecimento da diversidade sexual. Pois as pessoas travestis e transexuais enfrentam dificuldades ao buscarem atendimentos nos serviços públicos de saúde, não só quando reivindicam serviços especializados, como o processo transexualizador, mas também quando procuram outros atendimentos para suas demandas de saúde. Esta exclusão é reforçada pela trans/travestifobia que sofrem atrelada à discriminação por outros marcadores sociais, como pobreza, raça/cor, aparência física e escassez de serviços de saúde específicos para esta população (Mello, et al., 2011).

Todavia, nota-se também que o respeito à dignidade das pessoas desta comunidade ao acessar os serviços de saúde é afetado, pois, comumente, no atendimento não se pronuncia o nome social na acolhida que geram atitudes de desconfortos diante dos (as) profissionais de saúde, como também a necessidade de referenciar serviços específicos para atender pessoas LGBTQIA+ no sistema de saúde em hospitais voltados apenas para acometimentos relacionados a Infecções Sexualmente Transmissíveis (IST’s), contrapõe-se às normativas do direito à saúde universal equitativo no atendimento sanitário brasileiro (Dullius, 2019).

Corrobora, com o não acesso à saúde humanizada no sistema público de saúde para com LGBTQIA+, a não aplicação dos direitos legais dos usuários do Sistema Único de Saúde que garante o acolhimento sem discriminação, a gestão participativa, cogestão da assistência, clínica ampliada e compartilhada com os demais profissionais da rede de assistência, bem como a defesa dos direitos dos(as) usuários do sistema e dos(as) trabalhadores que estão inseridos nele (Brasil, 2013). 
Assim, oportunizar na formação profissional em saúde das juventudes universitárias através de debate das políticas de saúde integral às populações vulneráveis, que foram usadas como estratégia pedagógica pelos web seminários, possibilitando desconstruir discursos estereotipados sobre sexualidades e gêneros utilizando a comunicação digital na Internet como modos potencializador diálogos formativos nas graduações em saúde.

\section{Considerações Finais}

Os web seminários com as juventudes universitárias possibilitaram movimentar os dispositivos da comunicação digital na produção de práticas discursivas que apontaram outros modos de ensinar e aprender os conteúdos sobre as políticas de equidade em saúde, especialmente, com as populações LGBTQIA+. Contudo, observou-se lacunas na exploração deste conteúdo no que diz respeito à promoção de saúde na prática profissional no cotidiano da assistência direta com público no Sistema Único de Saúde.

Destarte, a pandemia da Covid-19 promoveu a urgência da utilização das Tecnologias Digitais de Informação e Comunicação, reforçando seus usos nas instituições educacionais, possibilitando as juventudes universitárias navegarem com profundidade no ciberespaço da Internet, desenhando outros cenários de produção de discursos substanciando práticas de assistência em saúde constituídas por modos éticos e políticos de garantir a vida para todos(as).

Assim, formar profissionais para atuarem com a saúde das pessoas, prescinde de compreenderem o cuidado ampliado e também utilizar as tecnologias digitais da comunicação como produtores de práticas de web cuidado, além de dá lugar às histórias de vidas, as singularidades, o respeito à diversidade sexual, de gêneros e a dignidade humana, pois deste modo se promovem a saúde como direito à vida.

A partir das contribuições dessa pesquisa faz-se necessária a realização de mais pesquisas em torno dessa temática e mais momentos com esses jovens universitários da área da saúde, para abordar mais questões sobre as demais populações de vulnerabilidades da nossa sociedade, com o intuito de promover uma melhoria do cuidado para os atendimentos nas unidades de saúde, visto que, a universidade é o local de ensino para esses futuros profissionais da saúde, e tem o dever de prepara-los para prestar um atendimento visando a equidade e integralidade da população à saúde.

\section{Agradecimentos}

À Universidade Estadual do Ceará (UECE), ao Programa de Pós-Graduação em Cuidados Clínicos em Enfermagem e Saúde, A Associação dos Jovens de Irajá - AJIR, ao Projeto de extensão Web Rádio AJIR. O presente trabalho foi realizado com apoio da Coordenação de Aperfeiçoamento de Pessoal de Nível Superior - Brasil (CAPES) - Código de Financiamento 001.

\section{Referências}

Antra, Associação Nacional De Travestis E Transexuais Do Brasil. (2019). Dossiê: assassinatos e violência contra travestis e transexuais no Brasil em 2018. Expressão Popular. https://antrabrasil.files.wordpress.com/2019/01/dossie-dos-assassinatos-e-violencia-contra-pessoas-trans-em-2018.pdf

Antra, Associação Nacional De Travestis E Transexuais Do Brasil. (2021). Dossiê: assassinatos e violência contra travestis e transexuais no Brasil em 2020. Expressão Popular. https://antrabrasil.files.wordpress.com/2021/01/dossie-trans-2021-29jan2021.pdf

Bourdieu, P. (2007). A economia das trocas simbólicas. Introdução, Organização e Seleção Sergio Miceli. São Paulo: Perspectiva.

Brasil, Ministério da Saúde. (2013). Portaria No 2.803, de 19 de Novembro de 2013. Brasília - DF. http://bvsms.saude.gov.br/bvs/saudelegis/g m/2013/prt2803_19_11_2013.html

Brasil, Ministério da Saúde. (2013). Política Nacional de Humanização - Humaniza SUS. Brasília - DF. https://bvsms.saude.gov.br/bvs/publicacoe s/politica_nacional_humanizacao_pnh_folheto.pdf 
Brasil, Conselho Nacional de Saúde. (2012). Resolução No 466, de 12 de dezembro de 2012. Brasília - DF. https://bvsms.saude.gov.br/b vs/saudelegis/cns/2013/res0466_12_12_2012.html

Butler, J. (1997). The Psychic Life of Power. Theories in Subjection.Standford, Standford University.

Dailius, W. R., Martins, L. B. \& McCleary, L. (2019) O holismo no treinamento dos profissionais de saúde para o atendimento ao publico LGBTQ+. revista unilab: revista brasileira de estudos da homocultura, 2 (2). https://doi.org/10.31560/2595-3206.2019.6.9961.

Foucault, M. (1988). História da sexualidade: a vontade de saber. Graal.

Foucault, M. (1996). A ordem do discurso. Loyola Editora.

Foucault, M. (2006). Poder e saber. Forense Universitária.

Foucault, M. (2012). As formações discursivas: A Arqueologia do Saber. Forense Universitária.

Foucault, M. (2013). A arqueologia do saber. Forense Universitária.

Foucault, M. (2015). História da Sexualidade. Paz \& Terra.

Foucault, M. (2018). A ordem do discurso. Loyola.

Fraser, N. (2003). Justice Social in the Age of Identity Politics. Verso.

Gastaldi, A. B. F., et al (2020). Observatório de Mortes Violentas de LGBTI+ no Brasil - 2020: Relatório. Acontece Arte e Política LGBTI+ \& Grupo Gay da Bahia, 1, 79.

Lemos, A. (2002). Cibercultura. tecnologia e vida social na cultura contemporânea. Sulina.

Lévy, P. (1996). O que é o virtual? Ed. 34.

Lévy, P. (1999). Cibercultura. Ed. 34.

Lionço, T. (2008). Que Direito à Saúde para a População GLBT? Considerando Direitos Humanos, Sexuais e Reprodutivos em Busca da Integralidade e da Equidade. Saúde e Sociedade, 17 (2), 11-21.

Mahdi, I., et al (2014). Survey of New Mexico School Health. Journal of School Health, 84 (1), 18-24.

Mallmann, E. M., et al (2012). "Fluência Tecnológica dos Tutores em Ambientes Virtuais". Revista Novas Tecnologias na Educação (RENOTE), 10 (1), 1-10.

Mello, L., Perilo, M., Braz, C. A. \& Pedrosa, C. (2011). Políticas de saúde para lésbicas, gays, bissexuais, travestis e transexuais no Brasil: em busca de universalidade, integralidade e equidade. Sex salud soc, 9, 7-28.

Paterson, B. L., Bottorff, J. L. \& Hewat, R. (2003). Blending observational methods: possibilities, strategies and challenges. International Journal of Qualitative Methods, 2 (1), 29-38.

Paulino, D. B., Rasera, E. F. \& Teixeira, F. B. (2019). Discursos sobre o cuidado em saúde de Lésbicas, Gays, Bissexuais, Travestis, Transexuais (LGBT) entre médicas(os) da Estratégia Saúde da Família. Interface. Comunicação, Saúde, Educação [online], 23, e180279. https://doi.org/10.1590/Interface.180279.

Polit, D. F. \& Beck, C. T. (2011). Fundamentos de Pesquisa em Enfermagem: Avaliação de Evidências para a Prática da Enfermagem. (7a ed.) Porto Alegre: Artmed.

Torres, R. A. M., et al. (2020). Youth vocabularies mediated on the webradio about human immune defense against Covid - 19. Research, Society and Development, 9 (12), e7091210731. https://doi.org/10.33448/rsd-v9i12.10731.

Torres, R. A. M., et al (2015). Comunicação em saúde: uso de uma web rádio com escolares. J. health inform, 7 (2), 58-61.

Torres, R. A. M. et al. (2019). Promotion of webcare in nursing through a WebRadio: knowledge of schoolage youth on collective health themes. Int $J$ Develop Res. 9 (2), p. 25661-6.

Torres, R. A. M., et al (2020a). Saúde mental das juventudes e COVID-19: discursos produtores do webcuidado educativo mediados na webrádio. Nursing, 23 (270), 4887-4896. https://doi.org/10.36489/nursing.2020v23i270p4887-4896.

Torres, R. A. M. et al. (2021). Health care on the radio: debate about sexuality and gender relations with school students. Brazilian Journal of Development, 7 , p. 28443-28454. https://doi.org/10.34117/bjdv7n3-522.

Unesco, (2020). A Comissão Futuros da Educação da Unesco apela ao planejamento antecipado contra o aumento das desigualdades após a COVID-19. Organização das Nações Unidas para a Educação, a Ciência e a Cultura. Paris, França. 